\title{
A High Throughput Screening Platform for Skin Tuning Properties from Natural Products: Identification of Skin Tanning Compounds
}

\author{
Gallant K. L. Chan, Kevin Q. Wu, Zack C. F. Wong, Aster H. Y. Fung, Xuyan Lin, Lucy J. Lou, \\ Tina T. Dong, Karl W. K. Tsim* \\ Division of Life Science and Center for Chinese Medicine R \& D, The Hong Kong University of Science and Technology, Hong Kong, \\ China \\ Email: ^botsim@ust.hk
}

How to cite this paper: Chan, G.K.L., Wu, K.Q., Wong, Z.C.F., Fung, A.H.Y., Lin, X.Y., Lou, L.J., Dong, T.T. and Tsim, K.W.K. (2016) A High Throughput Screening Platform for Skin Tuning Properties from Natural Products: Identification of Skin Tanning Compounds. Journal of Cosmetics, Dermatological Sciences and Applications, 6, 199-209.

http://dx.doi.org/10.4236/jcdsa.2016.65025

Received: November 4, 2016

Accepted: December 2, 2016

Published: December 5, 2016

Copyright $\odot 2016$ by authors and Scientific Research Publishing Inc. This work is licensed under the Creative Commons Attribution International License (CC BY 4.0).

http://creativecommons.org/licenses/by/4.0/ (c) (i) Open Access

\begin{abstract}
Skin lightening and tanning are two major areas dominating the market of skincare and cosmetic products. Though the demands are originated from two different communities, the two areas share a same goal-skin colour tuning. The known safe compounds with skin colour tuning activities are limited. In contrary, Chinese medicinal herb provides a pool of natural bioactive compounds, which have been used in Asian countries for long time and have been tested for its toxicity. Here, we demonstrate a high throughput screening platform for potential compounds usable for skin colour tuning. From 147 natural compounds, 26 of them showed potential in skin tanning functions by using the high throughput melanogenesis platform based on the melanogenesis assay on B16 melanocytes. Five of them promoted melanogenesis by over 50\%. Moreover, apart from 1, 8-dihydroxyanthraquinone, the other four compounds showed enhancement effect on tyrosinase activity. From the result, the compounds increased the Vmax of tyrosinase without changing the $\mathrm{Km}$ in a dosedependent manner. Thus, there should be no irreversible structural change of the enzyme. Definitely, this report contributes to the development of personalization in skincare and cosmetic products.
\end{abstract}

\section{Keywords}

Skin Lightening, Skin Tanning, High-Throughput Platform, Melanogenesis, Personalization, Skincare and Cosmetic Products

\section{Introduction}

The global cosmetics market increased from 127 billion euro to 181 billion euro with an 
average growth of $3.8 \%$ yearly in the last decade. According to the market information in 2014, the largest segment of cosmetic products belonged to skincare products, which shared 35\% of the global cosmetics market. Geographically, Asian Pacific represented $35 \%$ of the overall market sales, followed by Western Europe (22\%) and North America (21\%) [1]. Interestingly, the demands in skincare products of the populations of the two largest markets of cosmetics, the east (Asian Pacific) and the west (Western Europe), also go poles apart. According to an online international consumer survey including 6,600 cosmetic products consumers in 2014, the number of consumers in skin lightening products $(\sim 30 \%)$ doubled the number for skin tanning $(\sim 15 \%)$ in both India and China. The difference extended to six folds in Indonesia (30\% skin lightening products users over $5 \%$ skin tanning users). In Japan, the market almost completely dominated with skin lightening needs while nearly none of Japanese demanded on skin tanning products. The situations in Germany and France were just opposite. Less than 1\% of customers interested in skin lightening products and nearly the whole markets demanded for skin tanning products. The demands in skin lightening and tanning products were similar in countries located at the central region (e.g. Turkey and Russia). Seemingly, the differential demands in skin colour tuning were heavily depended on the matters of racial, geographical regions and cultures.

A collection of bioactive molecular tools was needed for making fine adjustment of skin colour, unfortunately, the choice for safe skin colour tuning was limited. Clinically, $2 \%$ hydroquinone was regarded as a golden standard for skin lightening [2]. However, the drug was prohibited by FDA in 2006 because of its potential risk in skin cancer. The derivatives of hydroquinone by adding a glycoside, named arbutin, was then developed to replace hydroquinone. But the low efficacy in skin lightening made arbutin being rejected by the market. New skin lightening agents like gallic acid from gallnut and kojic acid from the by-products of Japanese rice wine (i.e. Sake) were reported [3]. However, the mechanisms of tyrosinase inhibition of gallic acid and kojic acid is still under investigation. Some countries (e.g. Switzerland) banned kojic acid for the potential of tumour development in liver and thyroid under abnormally high dosage.

Recently, our group has reported a new skin lightening agents called $\mathrm{N}$-acetylneuraminic acid (NANA) [4]. NANA is a derivatives of monosaccharides derived from a natural health food supplement, ediblebird's nest (EBN; Yan Wo), or named cubilose. EBN is made of salivary secretion of specific swiftlets (e.g. Aerodramus fuciphagus). EBN has been consumed by the populations in China and Southeast Asian countries for its skincare function, especially for skin lightening, for over 800 years. The biological functions of EBN were not only well recorded in ancient Chinese literatures, but also reported in a list of scientific publications in previous years [5] [6] [7] [8]. EBN was not the only natural health food which recorded in the ancient Chinese literature for skincare functions. An ancient writing about several medicinal formula and acupunctural points was found in Dunhuang Grottoes (Grottoes of 400 - $1400 \mathrm{AD}$, located at the east of Dunhuang city, province, China) in 1907. The original copy is now preserved in the British museum. The Chinese version with explanatory notes was published in 1995 [9]. 
From the ancient writing found in Dunhuang Grottoes, some of the described Chinese medicinal formulations were related to skincare and haircare. The choice of Chinese medicines and their preparation methods were still adopted by Chinese medicine practitioner for the same medication today. Indeed, the pool of potential bioactive molecules derived from Chinese medicine was large. However, the work load in selecting the correct types of natural compounds was also tremendous. A high throughput screening platform for skin lightening function will definitely lower the hurdles.

\section{Materials and Methods}

\subsection{Chemicals}

One hundred and forty seven compounds natural compounds were purchased from the Center for Chinese Medicine, HKUST (Hong Kong, China). All compounds were preserved in lyophilized form at $-20^{\circ} \mathrm{C}$. A stock solution in DMSO at $100 \mathrm{mM}$ was prepared and filter sterilized before the experimental. Vitamin Cand kojic acid were purchased from Sigma-Aldrich (St. Louis, MO).

\subsection{Cell Culture Conditions}

B16 cells (CRL-6323 ${ }^{\mathrm{TM}}$; American Type Culture Collection (ATCC, Manassas, VA) was purchased and cultured according to the recommendations provided [10]. B16 cell was cultured in Dulbecco's Modified Eagle's Medium (DMEM, Invitrogen, Carlsbad, CA) supplemented with $10 \%$ fetal bovinealbumin and Penicillin-Streptomycin $(100 \mathrm{U} / \mathrm{mL})$ under $5 \% \mathrm{CO}_{2}$ and at $37^{\circ} \mathrm{C}$. Cells were sub-cultured every alternate day. Only passage between P8 to P18 of B16 could be served for the newly developed high throughput platform. Normally, the absorbance of the cultural medium should meet 0.5 - 0.7 at 405 $\mathrm{nm}$ within 4 days due to the accumulation of secreted melanosomes containing mature melanin. Cell passage failed to fulfill this criteria were regarded as disqualified and were not applied for the screening purpose.

\subsection{High Throughput Melanogenesis Assay on B16 Melanocytes}

Twenty thousand B16 cells was seeded onto each well of 96-well culture plates and incubated for $2-4$ days at $37^{\circ} \mathrm{C}$ with 1,10 or $100 \mu \mathrm{M}$ of all 147 natural compounds. Five $\mathrm{mM}$ of vitamin $\mathrm{C}$ and $2 \%$ kojic acid served as positive controls. The optical density of mixed solution was directly detected at $405 \mathrm{~nm}$, and the absorbance was converted to melanin concentration by a standard curve.

\subsection{Tyrosinase Assay}

The enzyme activity of mushroom tyrosinase (Sigma-Aldrich) was monitored by dopachrome formation at $492 \mathrm{~nm}$ through the oxidation of substrate (L-DOPA). The reaction medium $(200 \mu \mathrm{L})$ contained $0.5 \mathrm{mM}$ L-DOPA in $50 \mathrm{mM}$ sodium phosphate buffer ( $\mathrm{pH}$ 6.8) and ( $\mathrm{pH}$ 7.4). Five $\mathrm{mM}$ of vitamin $\mathrm{C}$ was used as an inhibitor control. The final concentration of mushroom tyrosinase was $0.2 \mathrm{mg} / \mathrm{mL}$. In this method, 0.1 $\mathrm{mL}$ of different concentrations of effectors was added to the reaction medium. The 
reaction mixtures were loaded on a 96-well plate, and the formation of dopachrome was measured in optical density at $492 \mathrm{~nm}$ after $20 \mathrm{~min}$ of incubation under dark at room temperature. Absorption was recorded using micro-plate spectrophotometer.

\subsection{Protein Assay and Statistical Tests}

Medium with melanosomes were removed completely after the measurement for melanogenesis. The concentration of protein was determined following the instructions of Bradford's method with a kit from Bio-Rad Laboratories (Hercules CA). The analysis was done on a 96-well microtiter plate. In brief, one part dye reagent concentrate was diluted with 4 parts of double distilled water before use. Six dilutions of BSA standard $(0.05-0.5 \mathrm{mg} / \mathrm{mL})$ were used for the test: Ten $\mu \mathrm{L}$ of each standard, or a sample solution, were added with $0.2 \mathrm{~mL}$ of diluted dye reagent into separate wells and mixed well. After $10 \mathrm{~min}$ incubation at room temperature, absorbance at $595 \mathrm{~nm}$ was taken. The concentration of protein was determined from the standard curve. Statistical tests were done by using student $t$ test and one way ANOVA provided in GraphPad Prism 5.0. Statistically significant changes was classed as $\left[{ }^{* * *}\right]$ where $\mathrm{p}<0.001$.

\section{Results and Discussion}

From the screening result of 147 natural compounds using the high throughput platform, twenty-six of them showed promotion effect on melanogenesis at varies levels (106\% - 220\% of basal level) (Data not shown). From which, five of them showed promising result in enhancing the formation of melanin, they were aristolochic acid I, nigakinone, astragaloside A, 1,8-dihydroxyanthraquinoneand quercetin-3-rhamnoside (Figure 1). All five compounds showed significant bioactivity at $100 \mu \mathrm{M}$ and were in a dose-dependent manner (Figure 2).

Tyrosinase is a key enzyme for melanogenesis converting tyrosine to L-DOPA, and then which further convertsto dopachromeas melanin. Melanin deposition on keratinocytes is the source of dark colour of skin. To further investigate the skin tanning mechanism of our newly screened out compounds, tyrosinase activity assay was applied. Similar to the result of B16 melanogenesis, the treatment of 5 compounds increased tyrosinase activity in dose-dependent manners. Although 1,8-dihydroxyanthraquinone did not show significant result, the overall pattern followed the result on B16 cells (Figure 3). Furthermore, the enzyme kinetic mechanism was then studied by applying Lineweaver-Burk plots. Apart from 1,8-dihydroxyanthraquinone, all four compounds successfully changed the Vmax (maximum enzyme activity velocity) in dosedependent manner without alteration of Km (Figure 4). Implying that the structure of tyrosinase should be stable without irreversibly conformational changed. The name, origin and the effects of compounds on Vmax of tyrosinase activity were summarized in Table 1.

The enhancement in tyrosinase activities, as reported here, could not be the only reason to account for the dramatic increase in melanogensis. Other than altering the tyrosinase activity, the followings could be considered as possible explanations for the 
<smiles>COc1cccc2c1cc([N+](=O)[O-])c1c(C(=O)O)cc3c(c12)OCO3</smiles>

Aristolochic acid I<smiles>COc1c(O)c(=O)n2c3ccccc3c3ccnc1c32</smiles>

Nigakinone

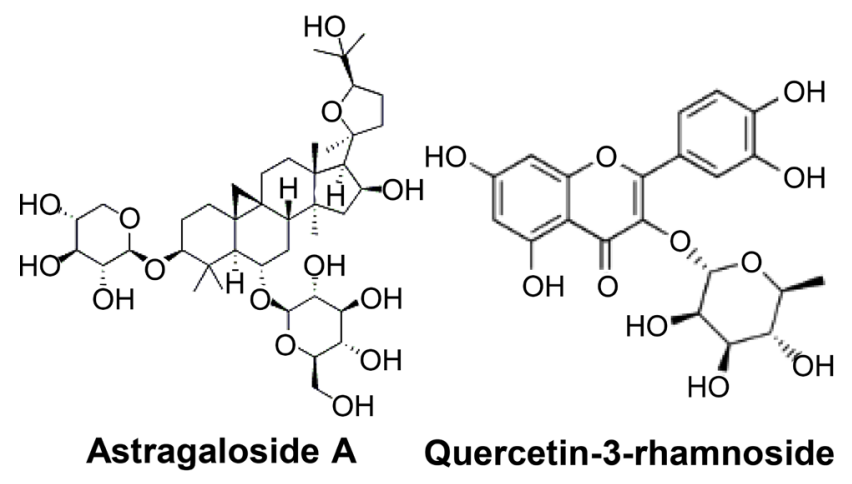<smiles>O=C1c2cccc(O)c2C(=O)c2cccc(O)c21</smiles>

\section{1, 8 - Dihydroxyanthraquinone}

Figure 1. Chemical structure of natural compounds with promoting effect on melanogenesis. Chemical structures of aristolochic acid I, nigakinone, as tragaloside A, 1,8-dihydroxyanthraquinone and quercetin-3-rhamnoside.

up regulation of melanogenesis induced by the identified compounds. Aristolochic acid I is an indicative compound found in Aristolochia spp. including Ma Dou Ling (Aristolochia debilis), Tian XianTeng (Aristolochia contorta), Qing Mu Xiang (Aristolochia cucurbitifolia), Guang Fang Ji (Aristolochia fangchi) and Guan Mu Tong (Aristolochia manshuriensis) [11]. Aristolochic acid I was reported to be an extremely potent compound associating with renal failure and urothelial cancer [12] [13]. Indeed, aristolochic acidI was the culprit of incident "Chinese herbs nephropathy" happened at Belgium in 2003. The promotion of melanin formation by aristolochic acid I could bean increase in tyrosinase expression via the Ras-MAPK pathway in B16 melonocytes: because which could mutate Ras and p53 [14]. Another possibility is that both aristolochic acid I and melanin share the same tyrosine-L-DOPA biosynthesis pathway. Despite the extremely high efficacy in skin tanning, aristolochic acid I is absolutely not recommended for skincare products development due to safety concerns. 


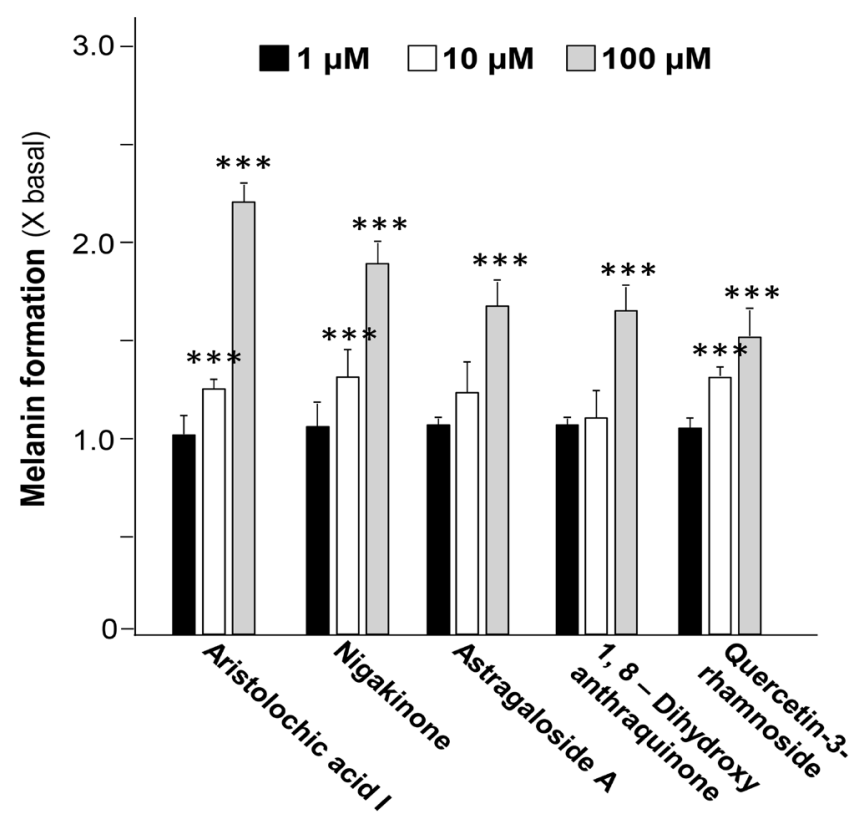

Figure 2. Natural compounds promote melanogenesis in B16 cell model. The promotion effect of 5 compounds including aristolochic acid I, nigakinone, astragaloside A, 1,8-dihydroxyanthraquinone and quercetin-3-rhamnoside from $1 \mu \mathrm{M}$ to $100 \mu \mathrm{M}$ on melanogenesis were showed. All data were presented as Mean \pm SD $(n=3)$. One-way ANOVA was performed on the data set by Graph Pad 5.0. Statistical significant differences were indicated. ${ }^{* *} \mathrm{p}<0.001$ versus control group (no drug treatment).

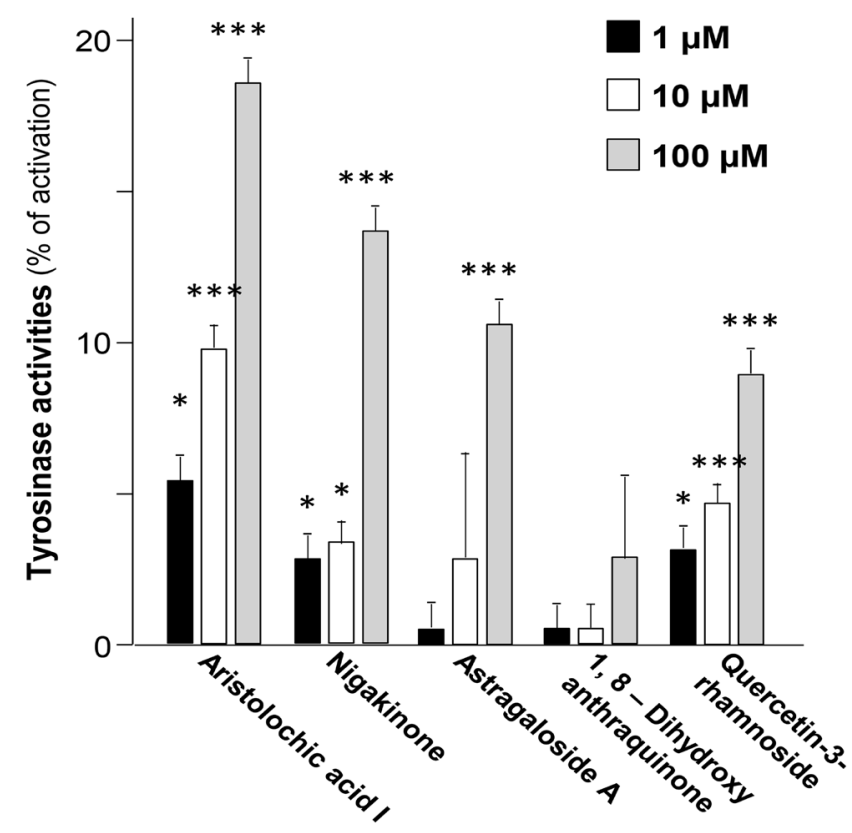

Figure 3. Natural compounds promote melanogenesis via activating tyrosinase activity. The 5 compounds including aristolochic acid I, nigakinone, astragaloside A, 1,8-dihydroxyanthraquinone and quercetin-3-rhamnoside from $1 \mu \mathrm{M}$ to $100 \mu \mathrm{M}$ reduced the activities of mushroom tyrosinase $(2 \mathrm{U})$. All data were presented as Mean $\pm \mathrm{SD}(n=3)$. One-way ANOVA was performed on the data set by Graph Pad 5.0. Statistical significant differences were indicated. ${ }^{*} \mathrm{p}<$ 0.01 and ${ }^{\star * *} \mathrm{p}<0.001$ versus control group (no drug treatment). 
Aristolochic acid I

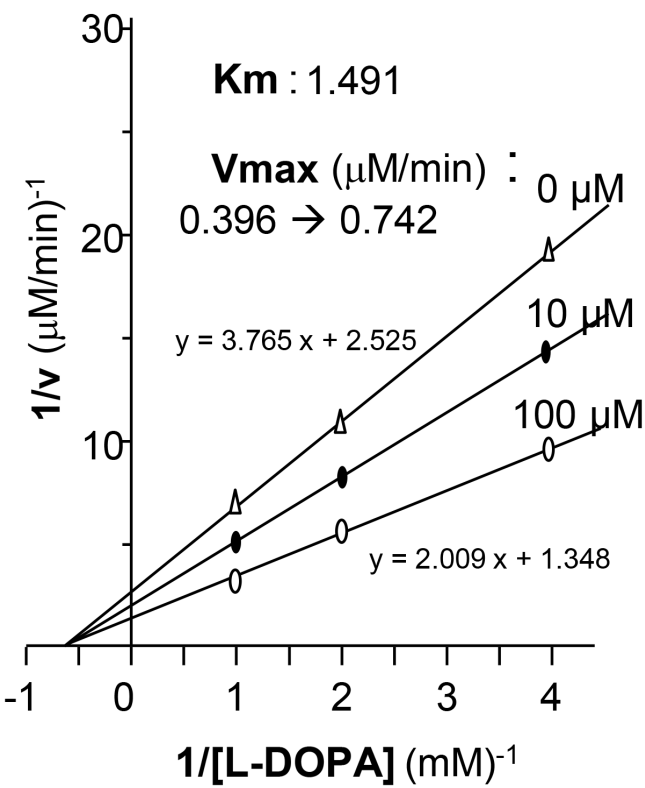

Astragaloside A

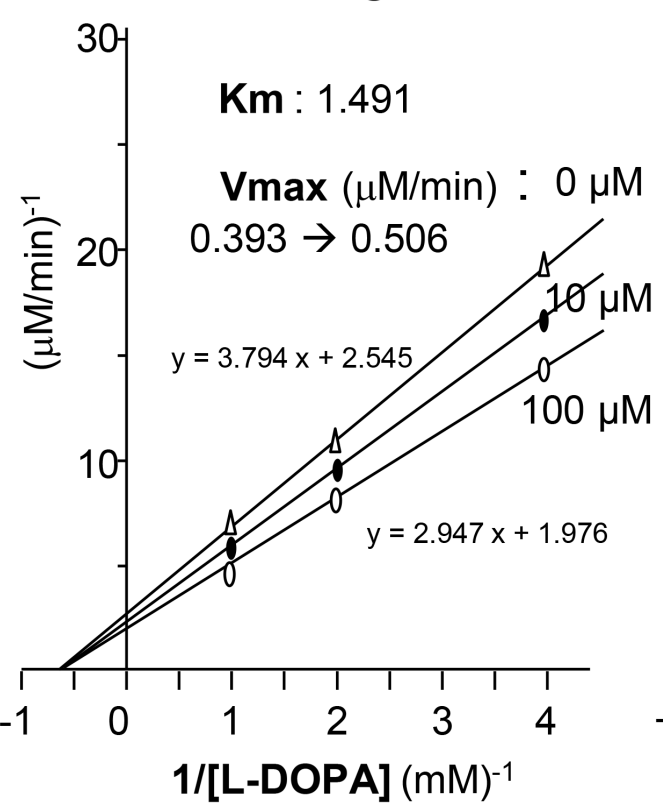

Nigakinone

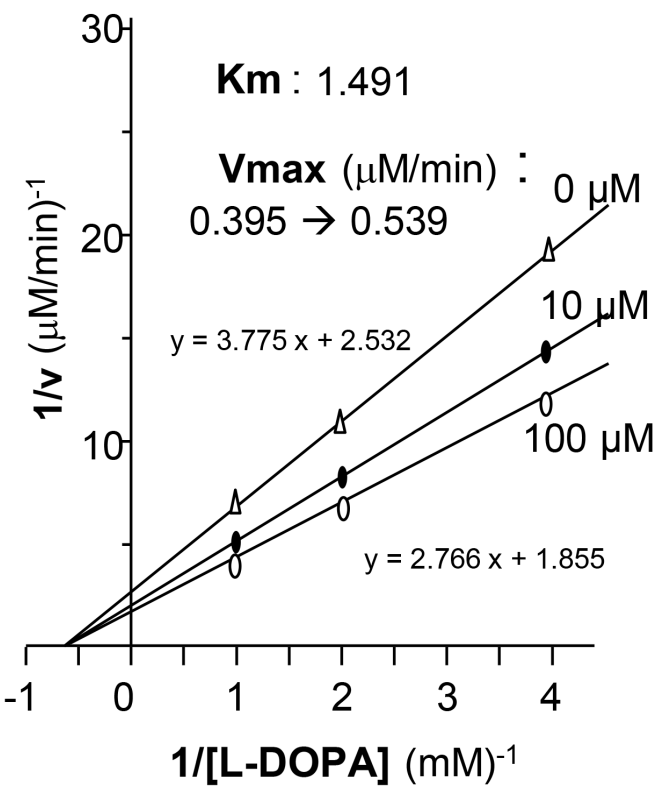

Quercetin-3rhamnoside

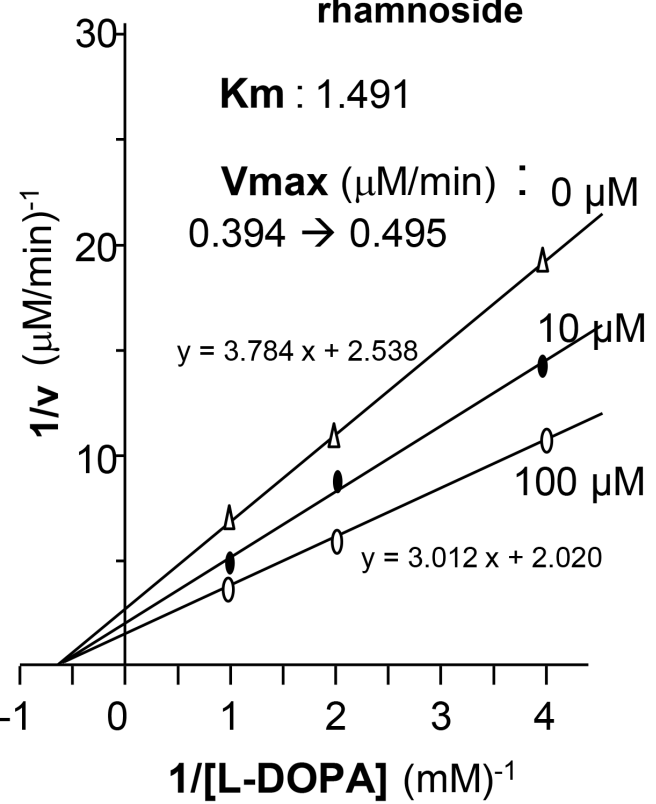

Figure 4. Activation mechanism of natural compounds on mushroom tyrosinase. The reaction rate of mushroom tyrosinase was defined as basal activity (i.e. $29.75 \mu \mathrm{M} / \mathrm{min}$ ) with a substrate of $0.5 \mathrm{mM}$ of L-DOPA. The activating effects of different natural compounds from $0 \mu \mathrm{M}$ to $100 \mu \mathrm{M}$ on mushroom tyrosinase activity were shown. The reaction velocity was calculated by the concentration of dopachrome, measured by spectrometer at $492 \mathrm{~nm}$ against time in min. Lineweaver-Burk plot of different concentrations of aristolochic acid I, nigakinone, astragaloside A and quercetin-3-rhamnoside on mushroom tyrosinase were illustrated. Mean values of $\mathrm{Km}$ and $\mathrm{Vmax}(n=3)$ were calculated by GraphPad 5.0 after plotting the activity of mushroom tyrosinase against the concentration of different compounds. Corresponding linear equations for $0 \mu \mathrm{M}$ and $100 \mu \mathrm{M}$ were also showed. 
Table 1. Variations in enzyme kinetics by the top five potential skin tanning compounds derived via the high throughput screening platform.

\begin{tabular}{cccc}
\hline Compound & Origin & Km & $\begin{array}{c}\text { Vmax } \\
\text { (at 100 } \mu \mathrm{M} \text { compound) }\end{array}$ \\
\hline Aristolochic acid I & Aristolochia clematitis & 1.491 & $0.396 \rightarrow 0.742$ \\
Nigakinone & Picrasma excelsa & 1.491 & $0.395 \rightarrow 0.539$ \\
Astragaloside A & Astragalus spp. & 1.491 & $0.393 \rightarrow 0.506$ \\
1, 8-Dihydroxyanthraquinone & Derived from anthraquinone & 1.491 & 0.394 \\
Quercetin-3-rhamnoside & Fagopyrumtataricum & 1.491 & $0.394 \rightarrow 0.495$ \\
\hline
\end{tabular}

Mean values of $\mathrm{Km}$ and Vmax were calculated by Graph Pad 5.0 after plotting the activity of mushroom tyrosinase against the concentration of different compounds using Lineweaver-Burk plot $(n=3)$.

Nigakinone was an alkaloid which corresponding to the "bitterness" of Picrasmae Ramuluset Folium, originated from Picrasma quassioides. The bitterness of Picrasmae Ramuluset Foliumis even stronger than quinine and is frequently used as febrifuge and insecticide. Nigakinone is also a popular supplement for treating stomachache and to stimulate the appetite [15]. Here, this is the first report about the skin tanning effect of nigakinone. Up to now, no mechanistic study about the tanning effect of nigakinone has been reported.

Astragaloside A is a specific bioactive compound of a well-famed Chinese medicine Astragalius Radix. According to Chinese medicinal theory, Astragalius Radix can promote circulation of "Qi", a form of vital energy, in our bodies. Many famous ancient Chinese decoctions included different ratio of Astragalius Radix. For the past decades, our group has studied several decoctions with Astragalius Radix, such as Danggui Buxue Tang [16] [17] [18]; Fo Shou San and Yu Ping Feng San [19] [20] [21]. Astragalius Radix was able to abolish the ubiquity in degradation system and resulted the accumulation of hypoxia inducible factor 1 alpha (HIF-1 $\alpha$ ) [22] [23]. Thus, a pseudo-hypoxic environment could be generated at cellular level. While melanocyte settling at the basal lamina of skin epidermal layer should be the most hypoxic region across multiple layers of skin [24]. The hypoxic microenvironment of skin could contribute to melanogenesis via HIF-1 $\alpha$ [25] and Akt pathway [24]. Possibly, astragalo side A could be one of the active components for abolishment of HIF-1 $\alpha$ degradation in melanocyte, and thus enhance the melanogenesis through Akt pathway. Our preliminary data showed an increase in content of HIF- $1 \alpha$ protein after a 24 hours treatment of astragalo side A on cultured A375 cell (human melanocytes). Certainly, more evidence is needed to elucidate the detail mechanism of the promotion effect in melanogenesis by astragalo side A.

Dihydroxyanthraquinone, also known as dantron, was synthetically derived from anthraquinone. This is a common laxative. No known report is describing the skin tanning function of dihydroxyanthraquinone. Structurally, dihydroxyanthraquinone contains 2 phenolic group that is a hallmark for skin lightening agent (e.g. hydroquinone). Anthraquinone is a redox active compound. It is possible that its derivative can undergo a distinct pathway for skin tanning without changing the activity of tyrosinase. Un- 
fortunately, dihydroxyanthraquinone was considered as carcinogen by the US FDA, and which may not be a good candidate for cosmetic product development. Similar to dihydroxyanthraquinone, quercetin-3-rhamnoside also contains several phenolic groups. Actually, quercetin-3-rhamnoside is a glycoside formed from the flavonoid quercetin and the deoxy sugar rhamnose. Quercetin is a non-specific protein kinase enzyme inhibitor, as well as its abilities to activate estrogen receptors.

Here, we demonstrated the application of a cell based high throughput platform for skin colour tuning using specialized B16 melanocytes. Compared to the general procedures of B16 melanogenesis assay, our newly developed method could be finished within 2 - 4 days depending on the basal melanogenesis activity without the need for cell lysis and extraction of melanin [10]. As the two major time consuming steps were skipped, the screening work for 147 compounds in this study only required 3 days while normally it took 2 weeks. In 2014, the authority of China launched new regulations on cosmetic and skincare products, mainly following the requirement of Europe. In Europe, the 3D human skin model is recommended for testing cosmetic products; however, which is time consuming and expensive [4]. The current established cell testing therefore could be an alternative.

\section{Conclusion}

In conclusion, a high throughput screening platform on skin colour tuning was developed. With a demonstration of using 147 natural compounds, several potential natural skin tanning agents with promising effect were found. With the newly invented platform, refined skin colour tuning for personalization in cosmetic and skincare products will become possible. Moreover, the newly discovered skin tanning agents could be added into skin protection products (e.g. sun block). The products will shorten the time of UV exposure to obtain same degree of skin tanning effect. Thus, the public risk for skin cancer will be largely reduced.

\section{Acknowledgements}

The paper is supported by Hong Kong Research Grants Council Theme-based Research Scheme (T13-607/12R), ITF (UIM/254), ITF (UIM/288), ITF (UIM/302), GRF (661110, 662911, 660411, 663012, 662713, M-HKUST604/13), TUYF12SC02, TUYF12SC03, TUYF15SC01, The Hong Kong Jockey Club Charities Trust (HKJCCT12SC01) and Foundation of The Awareness of Nature (TAON12SC01) to Karl Tsim. Zach Wong received a scholarship from HKJEBN Scholarship for Health and Quality Living.

\section{References}

[1] Ernst \& Young (2015) Seeking Sustainable Growth: The Luxury and Cosmetics Financial Factbook 2015 Edition.

[2] Elizabeth, T., Makino, B.S., Sujatha, S., Monya, L.S., Piyush, J., Ajay, B. and Rahul, C.M. (2013) Evaluation of a Hydroquinone-Free Skin brightening Product Using in Vitro Inhibition of Melanogenesis and Clinical Reduction of Ultraviolet-Induced Hyperpigmentation. Journal of Drugs in Dermatology, 12, 16-20. 
[3] Kumar, K.J., Vani, M.G., Wang, S.Y., Liao, J.W., Hsu, L.S., Yang, H.L. and Hseu, Y.C. (2013) In Vitro and in Vivo Studies Disclosed the Depigmenting Effects of Gallic Acid: A Novel Skin Lightening Agent for Hyperpigmentary Skin Diseases. Biofactors, 39, 259-270. https://doi.org/10.1002/biof.1064

[4] Chan, G.K., Wong, Z.C., Lam, K.Y., Cheng, L.K., Zhang, L.M., Lin, H., Dong, T.T. and Tsim, K.W. (2015) Edible Bird's Nest, an Asian Health Food Supplement, Possesses Skin Lightening Activities: Identification of N-Acetylneuraminic Acid as Active Ingredient. Journal of Cosmetics, Dermatological Sciences and Applications, 5, 262-274. https://doi.org/10.4236/jcdsa.2015.54032

[5] Rashed, A.A. and Nazaimoon, W.M. (2010) Effect of Edible Bird's Nest on Caco-2 Cell Proliferation. Journal of Food Technology, 8, 126-130. https://doi.org/10.3923/jftech.2010.126.130

[6] Roh, K.B., Lee, J., Kim, Y.S., Park, J., Kim, J.H., Lee, J. and Park, D. (2011) Mechanisms of Edible Bird's Nest Extract-Induced Proliferation of Human Adipose-Derived Stem Cells. Evidence-Based Complementary Alternative Medicine, 2012, 1-11. https://doi.org/10.1155/2012/797520

[7] Chan, G.K., Zheng, K.Y., Zhu, K.Y., Dong, T.T. and Tsim, K.W. (2013) Determination of Free N-Acetylneuraminic Acid in Edible Bird Nest: A Development of Chemical Marker for Quality Control. Journal of Ethnobiology and Traditional Medicine, 120, 620-628.

[8] Yang, M., Cheung, S.H., Li, S.C. and Cheung, H.Y. (2014) Establishment of a Holistic and Scientific Protocol for the Authentication and Quality Assurance of Edible Bird's Nest. Food Chemistry, 151, 271-278. https://doi.org/10.1016/j.foodchem.2013.11.007

[9] Zhang N. (1995) The Secret Formulations and Moxibustion Figures in Dunhuang Grottoes. Gansu Culture Press, Lanzhou.

[10] Kasraee, B., Hügin, A., Tran, C., Sorg, O. and Saura, J.H. (2004) Methimazole Is an Inhibitor of Melanin Synthesis in Cultured B16 Melanocytes. Journal of Investigative Dermatology, 122, 1338-1341. https://doi.org/10.1111/j.0022-202X.2004.22509.x

[11] Zhang, C., Wang, X., Shang, M., Yu, J., Xu, Y., Li, Z., Lei, L., Li, X., Cai, S. and Namba, T. (2006) Simultaneous Determination of Five Aristolochic Acids and Two Aristololactams in Aristolochia Plants by High-Performance Liquid Chromatography. Biomedical Chromatography, 20, 309-318. https://doi.org/10.1002/bmc.565

[12] Chang, C., Wang, Y., Yang, A. and Chiang, S. (2001) Rapidly Progressive Interstitial Renal Fibrosis Associated with Chinese Herbal Medications. American Journal of Nephrology, 21, 441-448. https://doi.org/10.1159/000046647

[13] Lord, G.M., Cook, T., Arlt, V.M., Schmeiser, H.H., Williams, G. and Pusey, C.D. (2001) Urothelial Malignant Disease and Chinese Herbal Nephropathy. The Lancet, 358, 1515-1516. https://doi.org/10.1016/S0140-6736(01)06576-X

[14] Chen, C.H., Dickman, K.G., Moriya, M., Zavadil, J., Sidorenko, V.S., Edwards, K.L., Gnatenko, D.V., Wu, L., Turesky, R.J., Wu, X.R., Pu, Y.S. and Grollman, A.P. (2012) Aristolochic Acid-Associated Urothelial Cancer in Taiwan. Proceedings of the National Academy of Sciences of the United States of America, 109, 8241-8246. https://doi.org/10.1073/pnas.1119920109

[15] Li, T.S.C. (2002) Chinese and Related North American Herbs Phytopharmacology and Therapeutic Values. CRC Press. Printed in New York Washington DC, 133, 273.

[16] Dong, T.T., Zhao, K.J., Gao, Q.T., Ji, Z.N., Zhu, T.T., Li, J., Duan, R., Cheung, A.W. and Tsim, K.W. (2006) Chemical and Biological Assessment of a Chinese Herbal Decoction Containing Radix Astragali and Radix Angelicae Sinensis: Determination of Drug Ratio in 
Having Optimized Properties. Journal of Agricultural and Food Chemistry, 54, 2767-2774. https://doi.org/10.1021/jf0531631

[17] Zhang, W.L., Zheng, K.Y., Zhu, K.Y., Zhan, J.Y., Bi, C.W., Chen, J.P., Du, C.Y., Zhao, K.J., Lau, D.T., Dong, T.T. and Tsim, K.W. (2012) Chemical and Biological Assessment of Angelica Herbal Decoction: Comparison of Different Preparations during Historical Applications. Phytomedicine, 19, 1042-1048. https://doi.org/10.1016/j.phymed.2012.07.009

[18] Gong, A.G., Li, N., Lau, K.M, Lee, P.S., Yan, L., Xu, M.L., Lam, C.T., Kong, A.Y., Lin, H.Q., Dong, T.T. and Tsim, K.W. (2015) Calycosin Orchestrates the Functions of Danggui Buxue Tang, a Chinese Herbal Decoction Composing of Astragali Radix and Angelica Sinensis Radix: An Evaluation by Using Calycosin-Knock out Herbal Extract. Journal of Ethnopharmacology, 168, 150-157. https://doi.org/10.1016/j.jep.2015.03.033

[19] Du, C.Y.Q. , Choi, R.C.Y., Zheng, K.Y.Z., Dong, T.T.X., Lau, D.T.W. and Tsim, K.W.K. (2013) Yu Ping Feng San, an Ancient Chinese Herbal Decoction Containing Astragali Radix, Atractylodis Macrocephalae Rhizoma \& Saposhnikoviae Radix, Regulates the Release of Cytokines in Murine Macrophages. PLoS ONE, 8, e78622.

https://doi.org/10.1371/journal.pone.0078622

[20] Du, C.Y., Zheng, K.Y.Z., Bi, C.W.C., Dong, T.T.X., Lin, H. and Tsim, K.W.K. (2015) Yu Ping Feng San, an Ancient Chinese Herbal Decoction, Induces Gene Expression of AntiViral Proteins and Inhibits Neuraminidase Activity. Phytotherapy Research, 29, 656-661. https://doi.org/10.1002/ptr.5290

[21] Lou, J.S., Yan, L., Bi, C.W.C., Chan, G.K.L., Wu, Q.Y., Liu, Y.L., Huang, Y., Yao, P., Du, C. Y.Q., Dong T.T.X. and Tsim, K.W. (2016) Yu Ping Feng San Reverses Cisplatin-Induced Multi-Drug Resistance in Lung Cancer Cells via Regulating Drug Transporters and p62/ TRAF6 Signalling. Scientific Reports, 6, Article Number: 31926. https://doi.org/10.1038/srep31926

[22] Zheng, K.Y., Choi, R.C., Xie, H.Q., Cheung, A.W., Guo, A.J., Leung, K.W., Chen, V.P., Bi, C.W., Zhu, K.Y., Chan, G.K., Fu, Q., Lau, D.T., Dong, T.T., Zhao, K.J. and Tsim, K.W. (2010) The Expression of Erythropoietin Triggered by Danggui Buxue Tang, a Chinese Herbal Decoction Prepared from Radix Astragali and Radix Angelicae Sinensis, Is Mediated by the Hypoxia-Inducible Factor in Cultured HEK293 T. Journal of Ethnopharmacology, 132, 259-267. https://doi.org/10.1016/j.jep.2010.08.029

[23] Zheng, K.Y., Choi, R.C., Cheung, A.W., Guo, A.J., Bi, C.W., Zhu, K.Y., Fu, Q., Du, Y., Zhang, W.L., Zhan, J.Y., Duan, R., Lau, D.T., Dong, T.T. and Tsim, K.W. (2011) Flavonoids from Radix Astragali Induce the Expression of Erythropoietin in Cultured Cells: A Signaling Mediated via the Accumulation of Hypoxia-Inducible Factor-1 $\alpha$. Journal of Agricultural and Food Chemistry, 59, 1697-1704. https://doi.org/10.1021/jf104018u

[24] Bedogni, B., Welford, S.M., Cassarino, D.S., Nickoloff, B.J., Giaccia, A.J. and Powell, M.B. (2005) The Hypoxic Microenvironment of the Skin Contributes to Akt-Mediated Melanocyte Transformation. Cancer Cell, 8, 443-454. https://doi.org/10.1016/j.ccr.2005.11.005

[25] Buscà, R., Berra, E., Gaggioli, C., Khaled, M., Bille, K., Marchetti, B., Thyss, R., Fitsialos, G., Larribère, L., Bertolotto, C., Virolle, T., Barbry, P., Pouysségur, J., Gilles, P. and Robert, B. (2005) Hypoxia-Inducible Factor $1 \alpha$ Is a New Target of Microphthalmia-Associated Transcription Factor (MITF) in Melanoma Cells. The Journal of Cell Biology, 170, 49-59. https://doi.org/10.1083/jcb.200501067 
Submit or recommend next manuscript to SCIRP and we will provide best service for you:

Accepting pre-submission inquiries through Email, Facebook, LinkedIn, Twitter, etc. A wide selection of journals (inclusive of 9 subjects, more than 200 journals)

Providing 24-hour high-quality service

User-friendly online submission system

Fair and swift peer-review system

Efficient typesetting and proofreading procedure

Display of the result of downloads and visits, as well as the number of cited articles

Maximum dissemination of your research work

Submit your manuscript at: http://papersubmission.scirp.org/

Or contact jcdsa@scirp.org 